\title{
Penerapan Nilai-Nilai Tabarru Dalam Prinsip Akuntansi Syariah Studi Kasus Pada Perusahaan Asuransi Prudential Syariah Tbk
}

\author{
Basri Basir MR ${ }^{1)}$ \\ ${ }^{1}$ Dosen Akuntansi Universitas Muhammadiyah Makassar \\ email: basri.basir@unismuh.ac.id
}

(Diterima: 26-Februari-2018; direvisi: 12-Maret-2018; dipublikasikan: 18-April-2018) akses terbuka dibawah licenci CC BY-NC-4.0 (https://creativecommons.org/licenses/by-nc/4.0/ ).

\begin{abstract}
Abstrak:
Asuransi syariah menurut Fatwa Dewan Syariah Nasional Majelis Ulama Indonesia (DSN-MUI) dalam fatwanya yaitu: ( $\mathrm{ta}$ "mim, takaful, tadhamun) adalah usaha saling melindungi dan tolong menolong di antara sejumlah orang atau pihak melalui investasi dalam bentuk asset atau tabarru" yang memberikan pola pengambilan untuk menghadapi resiko tertentu melalui akad (perikatan) yang sesuai dengan syariah. Dalam tulisan ini dibahas tentang apakah penerapan nilai nilai tabarru telah sesuai menurut prinsip akuntansi syariah studi kasus pada Perusahaan Agency asuransi Prudential Syariah Tbk, Penulisan ini menggunakan pendekatan kuantitatif dengan metode deskriptif Comparativ. Hasil penelitian ini menunjukkan bahwa danatabarru" diperoleh dari setoran dana peserta atau premi 50\% untuk dana tabarru", kemudian dana tabarru" yang diinvestasikan ke sektor lain dan akan memperoleh bagi hasil antara peserta dan nasabah, dana tabarru" ini digunakan untuk membayar klaim yang hanya untuk para peserta. Hasil penelitian ini juga dapat diketahui bahwa perusahaan Asuransi Prudential syariah Tbk mulai dari akad, kedudukan para pihak peserta dalam akad tabarru", pengelolaan, surplus underwriting, defisit underwriting sesuai dengan konsep syariah yang ditetapkan Fatwa No.53 Dewan Syariah Nasional MUI tahun 2006.
\end{abstract}

Kata Kunci: Tabarru, Prinsip akuntansi syariah, Prudential syariah

\section{PENDAHULUAN}

Pada saat ini, di Indonesia telah banyak lembaga keuangan yang beroperasi dengan Prinsip islami atau syariah, Perkembangannya yang sangat pesat dan sudah banyak diminati oleh masyarakat Indonesia yang mayoritas beragama Islam, dengan tingkat pertubuhan saat ini sudah mencapai 85,1 persen per Tahun 2010, (diambil dari data PP NU). Dengan tingginya minat masyarakat terhadap lembaga 
keuangan syariah belakangan sudah mulai berkembang perusahaan asuransi yang berprinsipkan syariah.Asuransi merupakan salah satu lembaga yang memiliki peranan penting di Indonesia, karena kegiatannya berperan dalam perlindungan resiko, menghimpun Dana masyarakat dari penerimaan premi. Asuransi adalah suatu kesepakatan bersama,antara anggota masyarakat untuk saling menjamin dan menanggung dengan cara mengumpulkan uang dan membuat sebuah tabungan dana keuangan bersama yang digunakan sebagai dana bantuan bagi yang ditimpa musibah atau resiko yang lain (Adnan, 2005:10), Keberadaan Asuransi Syariah di Indonesia merupakan sebuah kebutuhan yang harus dipenuhi, terutama setelah muncul perbankan syariah karena keduanya memiliki timbal-balik satu sama lain dalam mengelola keuangan dengan menggunakan sistem yang berbasis syariah. Hal ini merupakan bagian dari prinsip syariah, sebagaimana diatur dalam fatwa Dewan Syariah Nasional No.21/DSN-MUI/X/2001 tentang Pedoman Umum Asuransi Syariah di Indonesia yang menyatakan bahwa seluruh investasi yang dilakukan oleh perusahaan asuransi syariah harus dilakukan sesuai dengan syariah (DSN-MUI : 2001). prinsipta'awun (tolong-menolong) pada akad tabarru wajib melekat pada seluruh produk dan akad dalam asuransi syariah. Asuransi syariah seharusnya bisa menunjukkan perbedaan dari akuntansi konvensional, adanya pengembalian danatabarru dari perusahaan asuransi kepada nasabah merupakan hal yang tidak sesuai dengan prinsip dasar akad tabarru yang seharusnya bertujuan ta'awun (tolong menolong) bukan untuk dasar komersial.

Berdasarkan pemaparan di atas, maka dilakukan penelitian dengan tujuan untuk mengetahui apakah penerapan nilai nilai tabarru telah sesuai menurut prinsip akuntansi syariah studi kasus pada Perusahaan Agency asuransi Prudential Syariah Tbk.

\section{METODE}

\section{Pendekatan Penelitian}

Dalam penelitian ini peneliti menggunakan pendekatan penelitian kuantitatif. Penelitian kuantitatif adalah penelitian yang menekankan pada quality atau hal yang terpenting dari sifat suatu barang/jasa (sevila, 1993:22). Metode yang digunakan adalah Metode penelitian deskriptif, metode deskriftif adalah metode yang digunakan untuk menggambarkan atau menganalisa suatu hasil penelitian tetapi tidak digunakan untuk membuat kesimpulan yang lebih luas (Sugiyono, 2011:29). Metode kuantitatif diskriptif komparative juga bertujuan untuk menjelaskan meringkaskan berbagai kondisi situasi, atau berbagai variable yang timbul dimasyarakat yang menjadi objek penelitian. Format diskriftif ini dapat dilakukan pada penelitian studi kasus. Alasan dari penggunaan metode deskriftif kokparative ini 
Basri Basir MR, Penerapan Nilai-Nilai Tabarru Dalam Prinsip Akuntansi Syariah, Studi Kasus Pada

Perusahaan Asuransi Prudential Syariah Tbk. |67

karena tujuan dari penelitian untuk meneliti, menganalisa dan menjelaskan tentang evaluasi penerapan akad tabarru berkaitan dengan Pengakuan, Pengukuran, Penyajian dan pengungkapan.melalui model studi kasus.

\section{Metode Analisis Data}

Dalam menganalisa data, penelitian ini menggunakan metode deskriptif komparative yaitu metode yang dipakai untuk membantu menggambarkan keadaaan-keadaan yang mungkin terdapat dalam situasi dengan menjelaskan, menguraikan, menggambarkan keadaan objek penelitian sebenarnya berdasarkan fakta-fakta yang tampak atau sebagaimana adanya.

Teknik analisis data yang digunakan dalam penelitian ini adalah sebagai berikut:

1. Mengumpulkan data dan informasi yang relevan dengan tujuan penelitian. Data dan informasi yang terkait dengan penelitian berasal dari hasil wawancara dengan informan penelitian dan hasil dokumentasi terkait dengan akad tabarru yang terjadi di perusahaan asuransi prudential syariah Tbk.

2. Mereduksi data dengan memilih data-data yang penting dan memfokuskan pada hal-hal yang pokok. Hasil wawancara informan dan dokumentasi transaksi danatabarru dipilih yang terkait langsung dengan penerapan prinsip akuntansi.

Menyajikan data dalam bentuk penerapan akuntansi terhadap transaksi akad danatabarru mulai dari pengakuan penyikapan tanggung jawab pemegang kuasa dan pelaksananya studi kasus di perusahaan asuransi prudential Syariah Tbk. Hasil wawancara dan dokumen akad danatabarru kemudian dijadikan bahan analisis deskriptif melalui alur penjelasan penerapan prinsip akuntansi.

\section{HASIL DAN PEMBAHASAN}

\section{A. Pengakuan dan Pengukuran Dana Tabarru}

Perusahaan Agency Prudential Syariah Tbk pada saat menerima kontribusi/premi dari peserta diakui sebagai Kontribusi yang terdiri dari dana tabarru, investasi dan ujroh pengelola. Kemudian Kontribusi dari peserta diakui sebagai bagian dari dana tabarru' dalam dana peserta. Bagian kontribusi yang merupakan pendapatan ujroh/fee diakui sebagai ujroh pengelola dalam LSDU dan sebagai biaya (bagi pengelola) dalam laporan laba/rugi. Dan Bagian kontribusi yang merupakan investasi yang diakui sebagai dana investasi peserta dalam Neraca dan Dana Investasi Peserta.

Surplus/defisit underwriting dana tabarru oleh Perusahaan agency Prudential Syariah Tbk di ukur sebagai Seluruh surplus dana tabarru dan sebagai cadangan dana tabarru, 30\% disisihkan ke cadangan dana tabarru dan $70 \%$ untuk didistribusikan ke peserta dan Perusahaan.

Cadangan dana tabarru untuk peserta dan perusahaan di distribusikan sebesar $80 \%$ Untuk distribusi ke peserta dan 20\% untuk didistribusikan ke Perusahaan.Distribusi surplus underwriting dana tabarru ke peserta dan pengelola di akui sebagai pengurang surplus dalam laporan perubahan dana tabarru peserta.Pendapatan surplus underwriting dana tabarru yang diperoleh oleh perusahaan diakui pendapatan pembagian surplus underwriting dalam laporan laba/rugi perusahaan. Sehingga Surplus underwriting yang didistribusikan kepada peserta diakui bagian peserta atas surplus underwriting dana tabarru yang masih harus 
dibayar dalam kewajiban pada neraca perusahaan.

Pengakuan dan Pengukuran Dana tabarru dari hasil wawancara dengan Bapak Usman, S.Kom dan dokumen laporan keuangan bahwa kontribusi (dana peserta) yang dibayarkan oleh peserta sebahagian adalah iuran tabarru dan sebahagian lagi adalah investasi. Iuran tabarru dikenakan perbulan yang dihitung otomatis per produk asuransi yang dipilih oleh peserta dengan sistem komputerisasi dengan mempertimbangkan umur peserta, jenis kelamin, besar manfaat asuransi yang dipilih serta merokok atau tidaknya peserta pada saat pengajuan/pendaftaran.

Pada transaksi bapak Usman S.Kom yang menyetorkan kontribusi sebesar Rp. 500.000/Bulan dengan pekerjaan sebagai karyawan swasta, tidak merokok, usia 29 tahun, menikah, waktu kontribusi 10 tahun dan pilihan asuransi oleh peserta adalah PRUlink syariah assurance account, PRUcrisis cover benefit syariah 34, PRUmed syariah, PRUpersonal accident death\&disablement syariah dan PRUwaiver syariah 33 maka setelah dilakukan penginputan ke dalam program/aplikasi perusahaan akan terbentuk nilai-nilai diantaranya perkembangan investasi atas dana tabarru, besarnya iuran tabarru perbulan untuk setiap produk asuransi, biaya akuisisi serta besaran nilai pertanggungan untuk setiap produk asuransi.

Pada tahun 1 sampai dengan tahun ke 5 pertanggungan porsi danatabarru hanya sebesar $20 \%$ dari kontribusi dan $80 \%$ menjadi biaya wakalah/ujroh (biaya akuisisi). Adapun pengakuan dan pengukuran untuk transaksi di atas adalah sebagai berikut :
Penerbitan Polis Asuransi

\begin{tabular}{|l|r|r|}
\hline $\begin{array}{l}\text { Dr. Piutang } \\
\text { Kontribusi }\end{array}$ & 500.000 & \\
\hline $\begin{array}{l}\text { Cr. Ujroh } \\
\text { Pengelola }\end{array}$ & & 394.809 \\
\hline $\begin{array}{l}\text { Cr. Dana } \\
\text { Investasi } \\
\text { Peserta }\end{array}$ & & \\
\hline Cr. Tabarru & & 22.882 \\
\hline
\end{tabular}

\section{Penerimaan Pembayaran}

\begin{tabular}{|l|l|l|}
\hline Dr. Kas & 500.000 & \\
\hline Cr. Piutang & & 500.000 \\
Kontribusi & & \\
\hline
\end{tabular}

PT. Prudential Life Assurance Syariah dalam hal pengakuan dan pengukuran danatabarru telah sesuai dengan PSAK No. 108 yaitu pada paragraph 14, 15, 17 dan 20 terkait danatabarru. Pada saat perusahaan menyalurkan dana investasi dari dana peserta maka pengakuan dan pengukuran transaksinya adalah sebagai berikut yang telah sesuai prinsip akuntansi syariah dalam aspek pengakuan dan pengukuran.

\section{. B. Penyajian dan Pengungkapan}

Pada laporan keuangan Perusahaan Prudential Syariah Kantor Agency Makassar hanya sesuai dengan prinsip akuntansi syariah terkait PSAK N0. 108 paragraph 34 yaitu telah menyajikan danatabarru sebagai bagian dari dana peserta yang dipisahkan kewajiban dan ekuitas dalam neraca (posisi laporan keuangan).

Sedangkan untuk paragraph 32 dan 35 pada PSAK no. 108 Perusahaan Prudential Life Assurance Syariah belum mengungkapkan didalam laporan keuangannya penyajian perubahan dana tabarru terkait distribusi surplus/defisit underwriting dana tabarru kepada peserta dan distribusi surplus/defisit underwriting 
Basri Basir MR, Penerapan Nilai-Nilai Tabarru Dalam Prinsip Akuntansi Syariah, Studi Kasus Pada Perusahaan Asuransi Prudential Syariah Tbk. $\mid 69$

dana tabarru kepada entitas pengelola serta penyajian cadangan dana tabarru.

Berdasarkan dokumen laporan keuangan yang dirilis oleh PT. Prudential Life Assurance Syariah belum sepenuhnya sesuai dan hanya menyajikan 6 komponen, yaitu :

1) Laporan Posisi Keuangan (Neraca)

2) Laporan Surplus (Defisit) Underwriting Dana

\section{Tabarru}

3) Laporan Laba Rugi

4) Laporan Perubahan Ekuitas

5) Laporan Arus Kas

6) Catatan atas Laporan Keuangan

Laporan perubahan danatabarru merupakan laporan yang sangat penting untuk diungkapkan entitas pengelola karena laporan tersebut mengungkapkan arus distribusi danatabarru kepada peserta dan entitas pengelola setelah proses investasi.

Dari hasil penilitian ini sejalan dengan teori Muhammad Syakir Sula, (2004 : 176) sistem operasional Asuransi Syariah (takaful) mekanisme pengelolaan dana di bagi menjadi 2 yaitu rekening investasi (ada unsur tabungan) dan tabarru (yang tidak mengandung unsur tabungan). Sistem inilah sebagai implementasi dari akad takafuli sehingga Asuransi syariah dapat terhindar dari unsur gharar, maisir, selanjutnya kumpulan dana peserta ini di investasikan sesuai dengan prinsip Syariat Islam. Setiap keuntungan dari hasil investasi setelah di kurangi beban asuransi (klaim dan premi asuransi) akan di bagi menurut prinsip almudharabah dengan pembagian contoh 70 :30, 60:40 sesuai dengan perjanjian kerjasama perusahaan dan peserta.

\section{KESIMPULAN DAN SARAN}

Berdasarkan dari hasil penelitian dan pembahasan maka dapat ditarik kesimpulan sebagai berikut :

1. Perusahaan Prudential Life Assurance Syariah Kantor Agency Makassar secara umum telah menerapkan prinsip akuntansi Syariah untuk dana tabarru terkait pengakuan, pengkuran, pengungkapan dan peyajiannya. Tetapi untuk penyajian dan pengungkapan dalam PSAK masih ada Beberapa yang belum diterapkan karena belum menyajikan Laporan Perubahan Dana Tabarru terkait distribusi surplus/defisit underwriting dana tabarru' kepada peserta maupun kepada entitas pengelola.

2. Perusahaan Prudential secara prinsip operational telah menerapkan prinsip ta'awun (tolong menolong) sesuai Fatwa DSN-MUI no 53/DSNMUI/III/2006 yang direalisasikan pada akad tabarru yang di tuangkan dalam polis peserta. Hal ini memperlihatkan bahwa tidak terjadinya transfer risk (pemindahan resiko) dari peserta ke perusahaan seperti yang dijalankan oleh asuransi konvensional namun prinsip sharing risk (saling menanggung/tolong menolong) antara sesama peserta dan perusahaan hanya sebatas entitas pengelola dana peserta yang 
memperoleh pendapat dari biaya pengelolaan dana tersebut.

Berdasarkan hasil pembahasan dan kesimpulan yang telah dikemukakan oleh peneliti, maka saran yang dapat diajukan dalam penelitian ini untuk dijadikan bahan masukan yang berguna bagi pihak yang terkait, yaitu :

1. Disarankan agar Perusahaan Prudential Life Assurance Syariah menyajikan Laporan Perubahan Dana Tabarusesuai PSAKagar setiap pengguna laporan keuangan baik itu peserta maupun yang lainnya dapat melihat informasi arus distribusi surplus/defisit underwriting kepada peserta dan kepada entitas pengelola.

2. Disarankan agar agen pemasaran Perusahaan Prudential Life Assuarance Syariah Kantor Agency Makassar untuk tidak memasarkan produk asuransi syariah jika belum memahami secara utuh konsep dan prinsip utama asuransi syariah untuk menghindari terbentuknya stigma di masyarakat bahwa tidak ada perbedaan prinsip operasional asuransi syariah dengan konvensional karena pemahaman peserta yang ikut dalam asuransi syariah hanya bertujuan mencari keuntungan (komersial) dan mengabaikan prinsip ta'awun (tolong menolong) diantara para peserta yang merupakan amal jariyah dari peserta.

\section{DAFTAR RUJUKAN}

Adnan, Ahyar. Akuntansi Syariah : Arah, Prospek danTantangannya, Yogyakarta : UII Press, 2005.

Anshori, Hukum Asuransi Syariah, Jakarta :Sinar Grafika, 2007.

Ali, AM. Hasan.Asuransi dalam Perspektif Hukum Islam; SuatuTinjauan Analisis Historis, Teoritis, dan Praktis, Jakarta:Prenada Media, 2004.

Al Quran danTerjemahan, Bandung: Jabal, 2010 .

Anggraeni, Dampak Penerapan Pernyataan Standar Akuntansi Keuangan (PSAK) 108 pada Strategi Investasi PT. Asuransi Takaful Umum.Universitas Indonesia: Jakarta,2009.

Antonio, Muhammad Syafi'i. Asuransi dalam Perspektif Islam, Jakarta Syarikat Takaful Indonesia, 1994.

Anwar, Khoiril. Asuransi Syariah, Halal dan Masahat, Solo: PT. Tiga Serangkai Pustaka Mandiri, 2007.

Asuransi Syariah Sudah Harus jalankaan PSAK 108 , http://www.infobanknews.com/2010/1 2/bapepam-lkasuransi-srariah-harussudah-jalankan-psak-108-di-20111.

Auditing for Islamic Financial Institution (1998)

http://www.financialaccounting.com.

Chairmiza, PelaksanaanAkadTabarru' pada PT. Asuransi Takaful Cabang Banda Aceh.UniversitasSyiah Kuala. Banda Aceh, 2014.

Fatwa Dewan Syari'ah Nasional No: 21/DsnMui/X/2001 tentang Pedoman Umum Asuransi Syari'ah. 
Fatwa DSN-MUI Nomor 53/DSNMUI/III/2006 tentang Tabarru' dalam asuransi syariah.

Furchan, Arief. Pengantar Metode Penelitian Kualitatif, Surabaya: Usaha Nasional, 1992.

Ghoni, Abdul dan Erni Arianty.Akuntansi Asuransi Syariah (antaraTeoridanPraktik), Jakarta: INSCO Consulting, 2007.

Harahap, SofyanSafri. 2008. Kerangka Teori dan Tujuan Akuntansi Syariah. Pustaka Quantum. Jakarta.

Hasan, Pengantar Asuransi Syariah, Jakarta :Referensi (Gaung Persada Group), 2014.

Https://slidemateri.wordpress.com/category/ ekonomi/konvensional/asuransikonvensional/pengertian-dasarhukum-sejarah-dan-tujuan-berdiri/ (diaksesTanggal 22/06/2016).

Https://www.prudential.co.id (diaksesTanggal 09/10/2016)

Husein, Rahmat. Asuransi Takaful Selayang Pandang dalamWawasan Islam danEkonomi, Jakarta: LembagaPenerbitFE-UI, 1997

Iqbal, Muhammad. Asuransi Umum Syariah dalam Praktik, Jakarta: Gema Insani Pers, 2005.

Iwan Triyuwono, Akuntansi Syariah (perspektif, metodologi,dan teori edisi $1 \& 2$, Rajagrafindopustaka,/rajawalipr es2006 / 2009.

Iqbal,Muhaimin.AsuransiSyariahDalamPrak tik, Depok: GemaInsani, 2006.

Janwari.AsuransiSyariah,Bandung:Pustaka BaniQuraisy, Juli 2005.

NurulIchsan, Jurnal Kordina, Vol. 8 No. 2, KOPERTAIS Wil.1 DKI, 2007.
Qardhawi, Yusuf. Halal dan Haram dalam Islam, Jakarta: Rabbani Press, 1985.

Sabiq, Sayid. Fiqh as-Sunnah, Jilid II, Beirut: Dar al-Fikr, 1995

Sugiyono, MetodePenelitianKuantitatif, Kualitatif, dan R\&D,XX1 AlfabetaCV,Bandung 2011.Sastrawidjaja, Man Suparman. HukumAsuransi.Bandung : Alumni, 1997.

Sabrina ,tafakulHukum Asuransi. Dana tabarru jasindo Bandung: Alumni, 2016

Sevila, Consuelo G. PengantarMetodePenelitian, Jakarta: UIPRESS, 1993.

Sula, Muhammad Syakir. Asuransi Syariah (Life and General): Konsep dan Sistem Operasional, Jakarta: GemaInsani,2004.

Suwantri, Implementasi Akuntansi Asuransi Syariah dan PSAK No. 108 (StudiEmpiris: PT Asuransi Takaful Umum), Universitas Jember: Jember, 2013.

Wirdiyaningsih, Perwata atmadja dkk.Bank danAsuransi Islam di Indonesia, cet. 3, Jakarta :KencanaPredana Media, 2007. 